\title{
Aortic root and ascending aortic dilatation in patients with repaired tetralogy of Fallot. Determinants, rates of progression, impacts on outcomes and relations to branch pulmonary artery stenosis
}

\author{
Beatrice Bonello ${ }^{2,1^{*}}$, Sonya V Babu-Narayan ${ }^{2,3}$, Gerhard Diller ${ }^{3}$, Yumi Shiina ${ }^{2,3}$, Sylvain Beurtheret ${ }^{1,3}$, \\ Michael Gatzoulis ${ }^{3}$, Daryl Shore ${ }^{3}$ \\ From 16th Annual SCMR Scientific Sessions \\ San Francisco, CA, USA. 31 January - 3 February 2013
}

\section{Background}

We examined features, progression and relations to outcomes of aortic dilatation (AD) in adults with repaired tetralogy of fallot (rtoF).

\section{Materials and methods}

Retrospective study of 110 rtoF adults with native aorta, median age 30.9 (22.9-39.4) years were studied by cardiovascular magnetic resonance (CMR) at baseline, and at follow-up (median 6.3 [IQR:5.1-7.6] years). Aortic measurements were performed at sinus, sinotubular junction (STJ), and mid-ascending aorta level. $\mathrm{AD}$ was defined as diameter $>2$ standard deviations larger than published normal Z-Scores, according to the age and body surface area.

\section{Results}

Sixty three percent of patients had AD, sinus dilatation was observed in $61 \%$ of the patients (Figure 1A) and $22 \%$ of the patients had associated with sinus dilatation, ascending aorta (AscAo) dilatation(Figure 1B). STJ dilatation was present in $44 \%$. Aortic dimensions were normal in $47 \%$ of patients (Figure 1C). Predictors of sinus dilatation were age $(\mathrm{p}=0.009)$, male gender $(\mathrm{p}=0.039)$, previous Blalock-Taussig (BT) shunt $(\mathrm{p}=0.0004)$. Independent predictor was previous BT shunt $(\mathrm{p}=0.004)$. Predictors of STJ dilatation were pulmonary atresia (PAt) $(\mathrm{p}=0.02)$, previous Waterston shunt $(\mathrm{p}=0.005)$ and male gender $(\mathrm{p}=0.009)$. Independent predictors were PAt $(\mathrm{p}=0.01)$ and male gender ( $\mathrm{p}-0.02)$. Predictors of AscAo dilatation were age at repair $(\mathrm{p}=0.01)$, systemic hypertension $(\mathrm{p}=0,04)$, PAt $(\mathrm{p}<0.0001)$, male gender $(\mathrm{p}=0.0004)$. On ROC curve analysis, sinus diameter $>39 \mathrm{~mm}$ was strongly associated with AscAo (AUC0.90, $\mathrm{p}<0.0001$ ). Independent predictors of AscAo dilatation were PAt $(\mathrm{p}<0.0001)$ and male gender $(\mathrm{p}=0.004)$. No patient experienced any aorta related event during follow-up. Diameter increase was observed in 25\% of patients at sinus, $21 \%$ at STJ and in $35 \%$ at AscAo level, at a mean rate of $0.05 \pm 0.1,0.06 \pm 0.14$ and $0.12 \pm 0.26$ $\mathrm{mm} /$ year respectively. In those patients, the progression was superior to the one expected according to the normal growth with the age. There was no change of diameter observed in the remainder $53 \%$ of patients. No predictors of aortic diameter progression were found.

\section{Conclusions}

Aortic dilatation is common in patients with rtoF but rates of diameter increase in mid-term follow-up are low when assessed by serial CMR. However, when observed, the diameter progression is superior to the one expected with the age. Ascending aorta dilatation is likely when aortic sinus diameter is greater than $39 \mathrm{~mm}$. Our data provides guidance on the need of aortic intervention in contemporary adult cohort with rtoF.

${ }^{2}$ CMR unit, Royal Brompton Hospital, Londoon, UK

Full list of author information is available at the end of the article

(c) 2013 Bonello et al; licensee BioMed Central Ltd. This is an Open Access article distributed under the terms of the Creative Commons Attribution License (http://creativecommons.org/licenses/by/2.0), which permits unrestricted use, distribution, and reproduction in any medium, provided the original work is properly cited. 


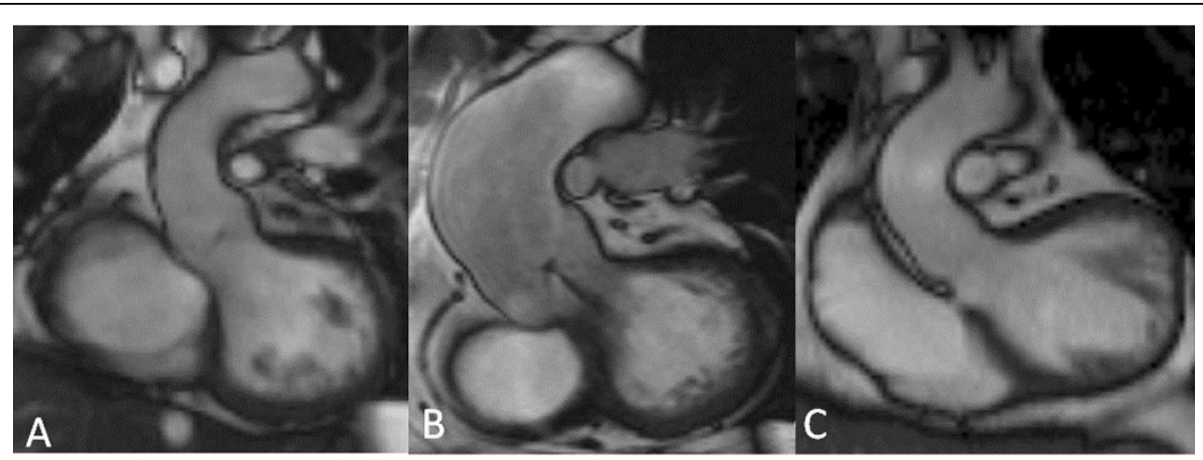

Figure 1

\section{Funding}

British Heart Foundation Fellowship (SVB-N).

French Federation of Cardiology (BB).

Unrestricted Actelion educational grant (GD).

The study was supported by the NIHR Cardiovascular Biomedical Research Unit of Royal Brompton and Harefield NHS Foundation Trust and Imperial College London.

\section{Author details}

${ }^{1}$ Congenital Heart Disease, CHU Timone Marseille, Marseille, France. ${ }^{2} \mathrm{CMR}$ unit, Royal Brompton Hospital, Londoon, UK. ${ }^{3}$ Congenital Heart Disease, Royal Brompton Hospital, London, UK.

Published: 30 January 2013

\section{doi:10.1186/1532-429X-15-S1-010}

Cite this article as: Bonello et al: Aortic root and ascending aortic dilatation in patients with repaired tetralogy of Fallot. Determinants, rates of progression, impacts on outcomes and relations to branch pulmonary artery stenosis. Journal of Cardiovascular Magnetic Resonance 2013 15(Suppl 1):0101.

\section{Submit your next manuscript to BioMed Central} and take full advantage of:

- Convenient online submission

- Thorough peer review

- No space constraints or color figure charges

- Immediate publication on acceptance

- Inclusion in PubMed, CAS, Scopus and Google Scholar

- Research which is freely available for redistribution 